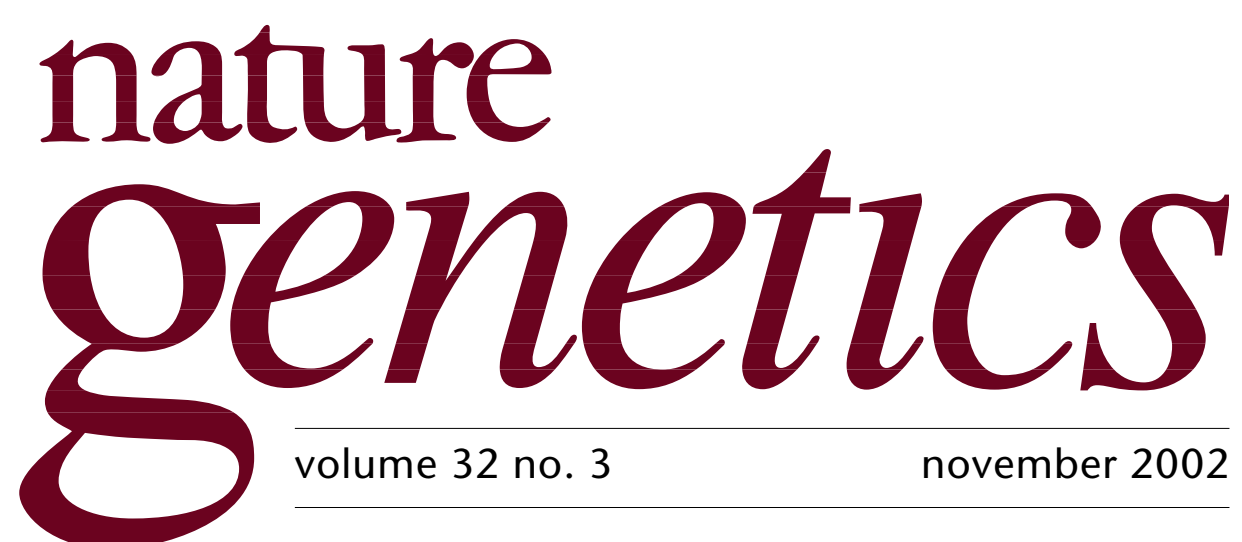

\title{
Coming to terms with microarrays
}

The stated objective of Nature Genetics, which appeared in the first issue, is to "provide professional researchers in the field with a vehicle for the publication of important research, and to provide a wider readership with a means of comprehending a field of research that is at once quickly moving, of great importance for scientific understanding and which promises powerfully to influence the development of society in the years ahead".

While our objective remains very much the same, the nature of some of our content has evolved over the past 10 years. We now publish papers that include a tremendous amount of data that would not be practical, or for that matter useful, to print in our pages. We have addressed this issue somewhat by publishing supplementary data on our website. But for some papers-those including microarray data in particular - the added space is still inadequate to fully disseminate the data and experimental conditions so that others in the field can replicate them. Perhaps more alarming is the concern that that the data are not being subjected to rigorous peer review. That review of these papers can be a monumental task is no secret; it has been less clear how we can ensure that we are judging these papers on the quality rather than just the quantity of data. Sparked by these concerns and an open letter from the Microarray Gene Expression Data (MGED) society, Nature Genetics, Nature and the other Nature research journals have agreed on a policy for submission and publication of papers containing microarray data.

In December of last year, we published a commentary by MGED (Nat. Genet. 29, 365-371; 2001) that proposed the Minimum Information about a Microarray Experiment (MIAME) guidelines. These guidelines were meant to clarify “...the minimum information required to ensure that microarray data can be easily interpreted and that results derived from its analysis can be independently verified". Although the MIAME proposal was presented as the first draft in an ongoing effort to standardize the reporting of microarray data, it seems clear that they are now sufficiently well accepted to begin to put some policies into place.

Effective 1 December, we will require that relevant papers submitted to Nature Genetics be accompanied by the mailing of five compact disks with data and information that complies with the MIAME guidelines. The manuscripts themselves should still be submitted through our online submission system, but the disks will also be provided to external reviewers. We specifically require that the MIAME checklist of variables be included with each of these papers (see http://www. 
mged.org/workgroups/MIAME/miame_checklist.html). We ask that this information not be sent in the form of compressed files sent by e-mail, as some reviewers may not have the programs necessary to decompress the files. We also ask that the data not be posted to your lab or institution website for purposes of review, in light of concerns over the confidentiality of the review process (although of course authors are free to post the data for their own purposes).

When a paper is accepted for publication, we will require that microarray data germane to the conclusions of the paper along with information compliant with the MIAME guidelines be submitted to one of two public repositories, GEO (http:// www.ncbi.nlm.nih.gov/geo/) or ArrayExpress (http://www.ebi.ac.uk/arrayexpress). As with sequence data, accession numbers for microarray data will be included in the methods section of the paper.

When microarray papers first appeared in our pages, they tended to be reports of genes whose expression went up or down as a result of simple changes in experimental conditions. This kind of expression catalog, although useful, has been replaced by more sophisticated experimental designs and protocols that use microarrays as a platform for probing specific phenotypes. In December, Nature Genetics will publish The Chipping Forecast II, our second supplement focusing on the microarray community and what is to come. The authors will supply descriptions of many of the analytic tools available, the basics of experimental design, and applications of array technology to several fields, as well as further information on standards and databases. We urge anyone interested in these exciting technologies to take a look.

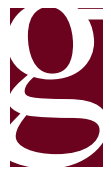

\section{Ch-Ch-Changes}

In the coming year Nature Genetics is going to evolve. Don't worry-we're still going to publish the highest quality genetics research. We're just interested in diversifying our content to better serve the interests of the genetics community. It's an exciting time for us, and we'd like to hear your comments on what kinds of content you would like to see in our research papers, commentaries, or whatever suits your fancy. Is there something you didn't like or, better, liked very much? We'd like to know. We have set up an e-mail address for comments and suggestions. Please feel free to get in touch with us at ngfeedback@natureny.com and let us know what you think.

Readers who are familiar with the masthead will already have noticed one change at Nature Genetics, which is that Bette Phimister has left the journal. Bette joined us as an assistant editor in 1996 and was appointed chief editor in June 2000. Our regular contributors, referees and readers will know that the degree to which the journal has achieved what it set out to do in the first issue is in large measure thanks to her contributions over the past six years. Her editorial colleagues are grateful for her leadership, and our sadness at seeing her go is tempered somewhat by the knowledge that we will continue to have her advice on an informal basis. We wish her well.

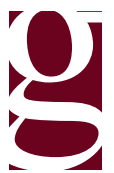

